\title{
Keinotekoisten lyhytpäiväkäsittelyiden ja varastoinnin vaikutus mansikan (Fragaria x ananassa Duch.) kukintaan ja satoon
}

\author{
Timo Hytönen, Katriina Mouhu ja Pauliina Palonen \\ Soveltavan biologian laitos, PL 27, 00014 Helsingin yliopisto, timo.hytonen@ helsinki.fi
}

\section{Johdanto}

Kasvihuonemansikan tuotannossa käytetään yleisesti mansikan lyhyenpäivänlajikkeita. Niiden kukintainduktiota säätelee ensisijaisesti valojakson pituus. Kukinnan kannalta kriittinen päivänpituus $15^{\circ} \mathrm{C}$ :een lämpötilassa on 12-16 h lajikkeesta riippuen, mutta optimaalinen päivänpituus on lyhyempi (Heide 1977, Sonsteby \& Nes 1998). Valojakson pituudella ja lämpötilalla on voimakas yhdysvaikutus. Lämpötilan laskiessa kukintainduktio voi tapahtua pidemmässä valojaksossa ja kukintainduktiolle kriittinen päivänpituus lyhenee lämpötilan noustessa (Guttridge 1985).

Lyhyt valojakso ja alhainen lämpötila saavat aikaan muutoksia myös mansikan vegetatiivisessa kasvussa. Näissä olosuhteissa lehtiruodit jäävät lyhyiksi ja kasvu hidastuu ja lopulta taimet vaipuvat osittaiseen lepotilaan (Jonkers 1965). Konsin ym. (2001) totesivat, että vegetatiivisen kasvun heikkeneminen vaatii lyhyemmän päivänpituuden tai alhaisemman lämpötilan kuin kukintainduktio. Lyhyessä valojaksossa rönsyjen tuotanto pysähtyy ja hankasilmuista alkaa muodostua sivuhaaroja (Guttridge 1985). Lisäksi päivänpituuden lyheneminen ja lämpötilan lasku lisäävät tärkkelyksen kerääntymistä mansikan juuriin (Maas 1986, Le Miere ym. 1996).

Kahdella peräkkäisellä lyhytpäiväkäsittelyllä (LP) voidaan saada kaksi peräkkäistä satoa Korona-lajikkeella (Mäki 1999). Keinotekoisesti lyhytpäiväkäsiteltyjen ja sen jälkeen varastoitujen taimien sopivuutta viljelyyn ei ole tutkittu. Tässä tutkimuksessa selvitetään kaksi peräkkäistä LP-käsittelyä saaneiden varastoitujen taimien käyttömahdollisuuksia ensisijaisesti kasvihuoneessa, mutta myös kausihuoneessa ja avomaalla. Lisäksi tutkitaan mansikan kukka-aiheiden muodostumista erilaisissa päivänpituuskäsittelyissä.

\section{Aineisto ja menetelmät \\ Taimimateriaali}

Kokeissa käytetyt mansikkalajikkeen Korona taimet kasvatettiin Helsingin yliopiston Viikin koekasvihuoneilla. Taimet lisättiin kesäkuussa 2001 rönsypistokkaista sumumonistuksella. Heinäkuussa taimet istutettiin Plantek 25 kennostoihin, joiden pottikoko on $8 \times 8 \times 9 \mathrm{~cm}$. Kokeen 1 taimet ruukutettiin $\varnothing 11 \mathrm{~cm}: n$ ruukkuihin ennen päivänpituuskäsittelyitä. Kasvualustana käytettiin Kekkilän B2-turvetta. Taimia kasteltiin päivittäin lannoiteliuoksella, jonka johtokyvyksi säädettiin $1 \mathrm{mS} / \mathrm{cm}^{2}$. Taimet pidettiin pitkänpäivänolosuhteissa valottamalla suurpainenatriumlampuilla klo 6.00-24.00 välisenä aikana. Lämpötila säädettiin $20^{\circ} \mathrm{C}$ :een.

\section{Koe 1: Kukka-aiheiden muodostuminen}

Korona-lajikkeen kukka-aiheiden muodostumista tutkittiin stereomikroskoopin avulla neljässä erilaisessa päivänpituuskäsittelyssä. Kaikki taimet laitettiin LP-käsittelyyn 27.9.2001. Käsittelyn 1 (K1) taimet siirrettiin pitkään päivään (PP) kolmen viikon LP-käsittelyn jälkeen. Käsittely 2 (K2) oli jaksotettu LP-käsittely: 3 viikkoa LP + 4 viikkoa PP + 3 viikkoa $L P$. Käsittelyn 3 (K3) taimet siirrettiin kolmen viikon LP-käsittelyn jälkeen kuudeksi viikoksi kylmävarastoon $-1{ }^{\circ} \mathrm{C}$ :seen. Neljännessä käsittelyssä (K4) taimet pidettiin LP:ssä 15 viikkoa. LP-käsittelyn aikana päivänpituus oli $12 \mathrm{~h}$ ja PP:ssä $18 \mathrm{~h}$ ja lämpötilat vastaavasti 15 ja $20^{\circ} \mathrm{C}$. LP-käsittelyt toteutettiin pimennysverhoilla varustetussa kasvihuoneosastossa ja PP vastaavassa verhottomassa osastossa.

Käsittelyistä otettiin viisi tainta mittauksiin kahden viikon välein. Viimeiset näytteet otettiin 15 viikon kuluttua käsittelyiden aloittamisesta. Kaikkien yli puolen cm:n mittaisten sivuhaarojen lukumäärät laskettiin. Kärkimeristeemit luokiteltiin vegetatiivisiksi tai generatiivisiksi stereomikroskoopin avulla. Meristeemin katsottiin olevan generatiivinen, kun kukka-aiheiden initaation alkuvaiheessa muodostuva kohouma oli selvästi näkyvissä meristeemin keskellä. Lisäksi laskettiin kukka-aiheiden lukumäärä. Tuloksista tehtiin faktorianalyysi NCSS 2000-ohjelmalla. Keskiarvojen vertailut tehtiin Tukeyn testillä.

\section{Koe 2: Lyhytpäiväkäsittelyiden ja varastoinnin vaikutus}

Korona-lajikkeen taimet laitettiin kahteen jaksotettuun ja yhteen pitkään LP-käsittelyyn syyskuun puolivälissä 2001. Jaksotetuissa käsittelyissä kahden kolmen viikon mittaisen LP-käsittelyn välissä oli joko kahden (K1) tai neljän (K2) viikon mittainen PP-jakso. Kolmas käsittely (K3) oli kymmenen viikon mittainen LPkäsittely. Päivänpituuskäsittelyissä olosuhteet olivat samat kuin kokeessa 1 . Käsittelyiden jälkeen taimet 
laitettiin LD-polyeteenistä (low density) valmistettuihin muovipusseihin ja varastoitiin kylmävarastossa $-1^{\circ} \mathrm{C}$ :ssa. Osa taimista laitettiin 12 ja 24 vuorokauden mittaisiin esikäsittelyihin $+4^{\circ} \mathrm{C}$ :een ennen varastointia.

Viidestä taimesta / käsittely puhdistettiin juuret viikoittain tärkkelysanalyysiä varten. Juurinäytteet kastettiin nestetyppeen ja pakastettiin $-70^{\circ} \mathrm{C}$ :ssa. Juuria kuivattiin pakkaskuivurissa kolme vuorokautta. Tämän jälkeen juuret jauhettiin ja jokaista juurinäytettä punnittiin $10 \mathrm{mg} 15 \mathrm{ml}: n$ putkiin. Liukoisia sokereita uutettiin näytteistä kolmesti puolen tunnin ajan milli-Q-vedellä. Jokaisen uuton jälkeen näytteet sentrifugoitiin ja supernatantti kaadettiin pois. Uuton jälkeen putkiin lisättiin $1 \mathrm{ml}$ asetaattipuskuria $(\mathrm{pH} 4,5)$ ja tärkkelyksen hydrolysoimiseksi $0,5 \mathrm{ml}$ amyloglukosidaasi-suspensiota $(4,44 \mathrm{mg} / \mathrm{ml}$ puskuria) ja näytteitä inkuboitiin 15 tuntia $55^{\circ} \mathrm{C}$ :ssa. Sentrifugoinnin jälkeen näytteiden glukoosipitoisuus mitattiin Trinder-reagenssilla (Sigma) spektrofotometrillä aallonpituudella $505 \mathrm{~nm}$.

Taimia otetaan hyötöön kasvihuoneeseen kuuden ja kymmenen viikon varastoinnin jälkeen. Taimet hyödetään kouruissa ruukkuihin istutettuina. Taimia hyödetään myös kausihuoneessa ja avomaalla harson alla keväällä 2002. Taimista havainnoidaan kehittyvien kukkien ja kukkavanojen lukumäärä ja kauppakelpoinen sato punnitaan. Vegetatiivista kasvua seurataan lehtiruotimittauksin. K1 ja K2:n taimista saadaan oletettavasti kaksi peräkkäistä satoa. Tuloksille tehdään faktorianalyysi NCSS 2000-ohjelmalla.

\section{Tulokset ja tulosten tarkastelu}

\section{Koe 1: Kukka-aiheiden muodostuminen}

Mittauksia on tähän mennessä tehty neljänä ensimmäisenä mittausajankohtana. Tässä esitetään vain käsittelyjen K1 ja K4 alustavia tuloksia.

Ensimmäiset kukka-aiheet olivat nähtävissä molemmissa käsittelyissä viiden viikon kuluttua päivänpituuskäsittelyjen aloittamisesta. Kukka-aiheiden määrä K4:ssä oli kasvanut molempina seuraavina mittausajankohtina. Sen sijaan K1:ssä ei ollut merkitsevästi enempää kukkia yhdeksän viikon jälkeen verrattuna seitsemän viikon jälkeen tehtyihin mittauksiin. Tällä mittausjaksolla ei tullut esiin käsittelyjen välisiä eroja kukka-aiheiden määrissä. Jahn \& Dana (1966) ja Le Miere ym. (1996) totesivat, että mansikalla kukka-aiheita muodostuu lisää vaikka taimet siirretään LP:stä ei-indusoiviin oloihin. Tekemiemme havaintojen mukaan uusien kukka-aiheiden indusoituminen pysähtyy Korona-lajikkeella, kun taimet siirretään ei-indusoiviin oloihin. Sen sijaan LP-käsittelyn aikana indusoituneiden kukka-aiheiden initaatio jatkuu.

Juurakon haaroja oli viiden viikon jälkeen enemmän K1:ssä kuin K4:ssä (Taulukko 1). Yhdeksän viikon jälkeen haaroja oli molemmissa käsittelyissä lähes saman verran. K4:ssä oli kuitenkin merkitsevästi enemmän generatiivisia ja K1:ssä vegetatiivisia sivuhaaroja. Ensimmäiset generatiiviset sivuhaarat havaittiin viiden viikon kuluttua päivänpituuskäsittelyiden aloittamisesta. Elsanta-lajikkeella kärkimeristeemin muuttuminen generatiiviseksi voidaan havaita noin kolmen viikon kuluttua 16 vuorokauden LP-käsittelyn alkamisesta (Taylor ym. 1997). Käsillä olevassa kokeessa havaintoja tehtiin kahden viikon välein. Siksi kärkimeristeemin muuttuminen generatiiviseksi havaittiin vasta viiden viikon jälkeen. Lisäksi lajike-erot ja erilaiset olosuhteet ovat vaikuttaneet meristeemien muuttumiseen vegetatiivisista generatiivisiksi. K1:ssä kolmen viikon LP-käsittely käynnisti juurakon haarojen muodostumisen. Haarat eivät kuitenkaan ehtineet kehittyä riittävän pitkälle LP-käsittelyn aikana, jotta ne olisivat voineet indusoitua kukintaan. Sivuhaaraan voi muodostua kukka-aiheita, kun siinä on vähintään 2-4 lehtiaihetta (Arney 1953, Jahn \& Dana 1970).

Taulukko 1. Kolmen viikon LP-käsittelyn (K1) ja jatkuvan LP:n (K4) vaikutus juurakon haarojen lukumääriin.

\begin{tabular}{cllllll}
\hline & \multicolumn{5}{l}{ Juurakon haarat } \\
\hline & Vegetatiivinen & Generatiivinen & \multicolumn{2}{c}{ Yhteensä } \\
\hline Aika käsittelyn alusta (vk) & $\mathrm{K} 1$ & $\mathrm{~K} 4$ & $\mathrm{~K} 1$ & $\mathrm{~K} 4$ & $\mathrm{~K} 1$ & $\mathrm{~K} 4$ \\
\hline 3 & 0 & 0 & 0 & 0 & 0 & 0 \\
5 & 2,8 & $1^{* *}$ & 0,8 & 0 & 3,6 & $1^{* * *}$ \\
7 & 3,6 & $2^{*}$ & 0,2 & $3 *$ & 3,8 & $5^{*}$ \\
9 & 5,8 & $3,2^{*}$ & 0 & $3,6^{* * *}$ & 5,8 & 6,8 \\
\hline
\end{tabular}

***(p<0,001), **(p<0,01) ja *(p<0,05) kuvaavat käsittelyjen välisiä eroja mittausajankohdittain.

Korona-lajikkeella voidaan saada kaksi peräkkäistä satoa kahdella peräkkäisellä LP-käsittelyllä (Mäki 1999). Kahden sadon mahdollisuus voidaan selittää tekemiemme havaintojen perusteella. Ensimmäisen LPkäsittelyn aikana kukintainduktio tapahtuu kärkimeristeemissä ja riittävän suuriksi kasvaneissa sivuhaaroissa. PP-jakson aikana kasvaneet vegetatiiviset sivuhaarat virittyvät kukintaan toisen LP-käsittelyn aikana. Käsillä olevassa kokeessa juurakon haaroja muodostui yhtä paljon K1:ssä ja K4:ssä. Koska muodostuvien 
kukka-aiheiden määrä on riippuvainen juurakon haarojen määrästä, voidaan jaksotetulla LP-käsittelyllä, ainakin teoriassa, saada yhtä paljon kukkia kuin jatkuvalla käsittelyllä. Sadon jaksottamisen lisäksi kahta erillistä LP-käsittelyä voidaan käyttää yhden pitkän käsittelyn sijasta, jos halutaan estää taimien vaipuminen osittaiseen lepotilaan ja varmistaa voimakas vegetatiivinen kasvu käsittelyiden jälkeen.

\section{Koe 2: Lyhytpäiväkäsittelyiden ja varastoinnin vaikutus}

Tämän kokeen osalta käsitellään ainoastaan tärkkelysmääritysten alustavia tuloksia. Jatkuvassa LP:ssä olleisiin taimiin kerääntyi enemmän tärkkelystä kuin jaksotetuissa käsittelyissä (Kuvio 1). PP-jakso kahden LPkäsittelyn välissä hidasti tärkkelyksen kerääntymistä juuriin. Myös Maas (1986) havaitsi, että päivänpituuden pidentäminen 12:sta 16:een tuntiin vähensi tärkkelyksen kerääntymistä juuriin. Käsillä olevassa kokeessa juurten tärkkelyspitoisuus oli viimeisellä mittauskerralla käsittelystä riippuen 165-295 mg/g kuivapainoa. Le Mieren ym. (1996) Englannissa tekemissä kokeissa tärkkelystä kerääntyi mansikan juuriin vain noin $70 \mathrm{mg} / \mathrm{g}$ kuivapainoa $15^{\circ} \mathrm{C}$ :een lämpötilassa luonnollisessa lyhenevässä päivänpituudessa. Suuri ero johtuu ilmeisesti eroista valo-oloissa. Suurpainenatriumlampuilla lyhyen valojakson aikana annettu lisävalo näyttäisi lisäävän tärkkelyksen määrää juurissa. Bringhurstin ym. (1960) mukaan juurten tärkkelys-pitoisuuden nousu parantaa taimien varastokestävyytä ja varastoinnin jälkeistä kasvuunlähtöä. Tämän perusteella jatkuvan LP-käsittelyn saaneet taimet olisivat sopivampia pitkäaikaiseen varastointiin kuin jaksotetussa käsittelyssä olleet taimet.

\section{Juurten tärkkelyspitoisuus}

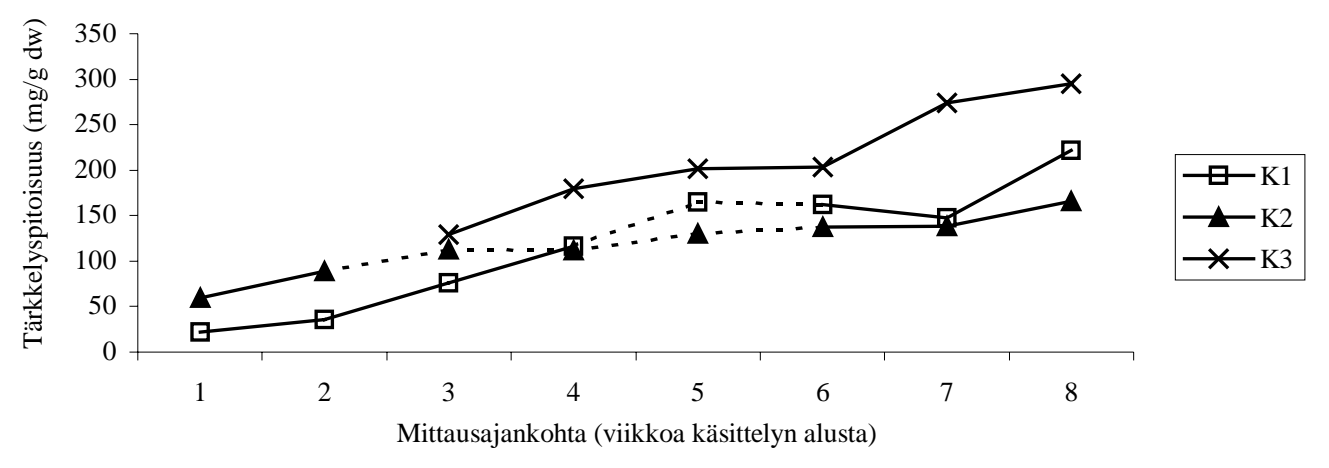

Kuvio 1. Päivänpituuskäsittelyiden vaikutus mansikan juurten tärkkelyspitoisuuteen. K1 $=3$ viikkoa LP +2 viikkoa $P P+3$ viikkoa $L P, K 2=3$ viikkoa $L P+4$ viikkoa $P P+3$ viikkoa $L P, K 3=10$ viikkoa $L P$. PP merkitty katkoviivalla.

\section{Johtopäätökset}

Kokeessa 1 uusien kukka-aiheiden muodostuminen loppui kolmen viikon LP-käsittelyn saaneilla taimilla seitsemän viikon jälkeen. Kolmen viikon LP-käsittelyssä juurakon haaroja muodostui yhtä paljon kuin jatkuvassa LP:ssä, mutta haarat jäivät vegetatiivisiksi. Tämä osoittaa, että taimien siirtäminen ei-indusoiviin oloihin LP-käsittelyn jälkeen estää uusien kukka-aiheiden indusoitumisen. Indusoituneiden kukka-aiheiden initaatio kuitenkin jatkuu PP-oloissa. Koska juurakon haaroja muodostui kolmen viikon LP-käsittelyssä yhtä paljon kuin jatkuvassa LP:ssä, voidaan jaksotetulla käsittelyllä, ainakin teoriassa, saada yhtä paljon kukkia kuin jatkuvalla käsittelyllä. Sadon jaksottamisen lisäksi kahta erillistä LP-käsittelyä voidaan käyttää yhden pitkän käsittelyn sijasta, jos halutaan estää taimien vaipuminen osittaiseen lepotilaan ja varmistaa voimakas vegetatiivinen kasvu käsittelyiden jälkeen.

Juurien tärkkelyspitoisuus oli suurempi jatkuvassa LP-käsittelyssä kuin jaksotetuissa käsittelyissä. Tärkkelyspitoisuuden tiedetään korreloivan positiivisesti taimien varastokestävyyden ja varastoinnin jälkeisen kasvuunlähdön kanssa. Siksi jatkuvan LP-käsittelyn saaneet taimet ovat todennäköisesti sopivampia pitkäaikaiseen varastointiin kuin jaksotetussa käsittelyssä olleet taimet.

\section{Kirjallisuus}

Arney, S. E. 1953. Studies of the growth and development of the genus Fragaria. II. The initiation, growth and emergence of leaf primordia in Fragaria. Annals of Botany 17: 477-492.

Bringhurst, R. S., Voth, V. \& Van Hook, D. 1960. Relationship of root starch content and chilling history to performance of Californian strawberries. Proceedings of the American Society for Horticultural Science 75: $373-381$.

Guttridge, C. 1985. Fragaria x ananassa. In: Halevy, A. (ed.). CRC Handbook of flowering. Vol. III. Boca Raton: CRC press. p. 16-33. 
Heide, O. M. 1977. Photoperiod and temperature interactions in growth and flowering of strawberry. Physiologia Plantarum 40: 21-26.

Jahn, O. L. \& Dana, M. N. Dormancy and growth of the strawberry plant. Proceedings of the American Society for Horticultural Science 89: 322-330.

Jahn, O. L. \& Dana, M. N. 1970. Crown and inflorescence development in the strawberry, Fragaria $x$ ananassa. American Journal of Botany 57: 605-612.

Jonkers, H. 1965. On the flower formation, the dormancy and the early forcing of strawberries. Mededelingen van de Landbouwhogeschool. Thesis, Wageningen.

Konsin, M., Voipio, I. \& Palonen, P. 2001. Influence of photoperiod and duration of short-day treatment on vegetative growth and flowering of strawberry (Fragaria x ananassa Duch.). Journal of Horticultural Science and Biotechnology 76: 77-82.

Le Miere, P., Hadley, P., Darby, J. \& Battey, N. 1996. The effect of temperature and photoperiod on the rate of flower initiation and the onset of dormancy in the strawberry (Fragaria $x$ ananassa Duch.). Journal of Horticultural Science 71: 361-371.

Maas, J.L. 1986. Photoperiod and temperature effects on starch accumulation in strawberry roots. Advances in Strawberry Production 5: 22-24.

Mäki, H. 1999. Toisen lyhytpäiväkäsittelyn vaikutus Korona-mansikan kukkien lukumäärään ja kukinnan ajoittumiseen. Maatalouden tutkimuskeskuksen julkaisuja, Sarja A, 67: 133-139.

Sonsteby, A. \& Nes, A. 1998. Short days and temperature effects on growth and flowering in strawberry (Fragaria x ananassa Duch.). Journal of Horticultural Science and Biotechnology 73: 730-736.

Taylor, D. R., Atkey, P. T., Wickenden, M. F. \& Crisp, C. M. 1997. A morphological study of flower initation and development in strawberry (Fragaria x ananassa) using cryo-scanning electron microscopy. Annals of Applied Biology 130: $141-152$. 